\title{
Quantity Surveying Undergraduates' Awareness on Cost Significant of High-Rise Condominium Projects in Malaysia: The Case of a Private University in Malaysia
}

\author{
Lee Wah Peng ${ }^{1, a}$, Ng See Seng ${ }^{1}$, Toh Tien Choon ${ }^{1}$, Lim Cheng Sim ${ }^{1}$, Yong Ching Khian ${ }^{2}$ and Goh Kai \\ Chen ${ }^{3, \mathrm{f}}$ \\ ${ }^{1}$ Department of Surveying, Lee Kong Chian Faculty of Engineering and Science, Universiti Tunku Abdul Rahman, \\ 43000 Kajang, Selangor, Malaysia \\ ${ }^{2}$ Department of Mathematical and Actuarial Sciences, Lee Kong Chian Faculty of Engineering and Science, \\ Universiti Tunku Abdul Rahman, 43000 Kajang, Selangor, Malaysia \\ ${ }^{3}$ Department of Construction Management, Faculty of Technology Management and Business, Universiti Tun \\ Hussein Onn Malaysia, 86400 Parit Raja, Johor, Malaysia
}

\begin{abstract}
Recent developments in quantity surveying (QS) emphasised the importance of identifying cost significant elements (CSE). The knowledge on CSE of high-rise condominium projects (HRCP) is essential as high-rise residential multi-unit projects are the next option in building construction due to limited land areas in urban areas. This study aims to determine the levels of awareness among QS undergraduates of a private university in Malaysia on CSE of HRCP in Malaysia. The respondents' knowledge on CSE has not achieved a satisfactory level. Both male and female respondents have the same levels of awareness on CSE. Remedial strategies to improve this situation are recommended.
\end{abstract}

\section{Introduction}

Cost significant technique is a cost estimating method. Poh and Horner [1] demonstrated the way the cost-significance theory can create a simple, well-structured, and sufficiently accurate measurement method by deriving a cost-significant model for student hostels in Singapore. Using a cost significant technique, Tas and Yaman [2] developed a generic computer-based cost estimating model for Turkish public building construction projects for use in their detailed design phase. These studies produced their cost significant estimating models based on cost significant items or work packages. However, recent developments in the area of QS underscored the importance of identifying CSE. Cartlidge [3] explained that for elemental cost estimating for building works, cost checking on the CSE must be conducted against every pre-established cost target from the Formal Cost Plan 2 Stage. Obviously, different types of buildings will have different CSE. The one and only comprehensive theory on CSE and their effects can be found in Smith and Jaggar [4]. They provided a good explanation on CSE and their effects for high-density residential multi-unit projects.

HRCP can be seen easily in urban or city areas because housing developments are moving towards constructing vertically rather than horizontally due to limited land areas. The cost planner should be able to make all project team members aware of the implications of any decision that they make on the

\footnotetext{
${ }^{a}$ Corresponding author : leewp@utar.edu.my
} 
building's design. Hence, this requires the cost planner to be equipped with a sound knowledge on CSE. This knowledge can be learned from courses during the study in the university or from working experiences. In the HRCP, the CSE are: Frame (Columns, Upper Floors), Finishes (Wall, Ceiling and Floor), Envelope (External Walls and Windows), Services, Internal Subdivision (Internal Walls, Screens and Doors), Preliminaries, and Fittings whereas the non CSE are: External Doors, Stairs, Roof, External Works, and Substructure [4]. Studies on CSE are vital, new, and so far, only received little attention both in Malaysia and overseas. So, this study aims to determine the levels of awareness among QS undergraduates of a private university in Malaysia on CSE of HRCP in Malaysia.

\section{Method}

The quantitative approach, specifically, a questionnaire survey methodology is adopted in this study in determining the levels of awareness among QS undergraduates on CSE of HRCP. Questionnaire responses based on a Likert scale $(1=$ strongly disagree, $2=$ disagree, $3=$ neither agree nor disagree, $4=$ agree, $5=$ strongly agree) can be utilised to effectively and efficiently test their understandings on the knowledge about CSE compared with the qualitative approach where the data are to be collected in the form of words or texts. In the January 2015 trimester, the total of 219 QS undergraduates who are in their third year out of the four-year bachelor degree programme, have been invited to take part in the questionnaire survey. These students became the targeted respondents because they have been exposed to subjects such as construction technologies, construction measurements and estimating, and construction economics. This means that they should already have the knowledge necessary for identifying CSE of a building. The final year QS undergraduates are not being targeted in this study because it would be difficult to implement any remedial strategies if later on it was to be found that their levels of awareness on CSE was actually low, seeing that they have graduated by then.

An online version of the survey questionnaire has been developed using the systems provided by SurveyMonkey.com. Before the full-fledged survey is carried out, a pilot study is conducted with 3 academic staffs and 7 respondents in identifying the weaknesses in the survey questionnaire. It is found that all of them are very satisfied with the survey questionnaire and thus the first draft of the survey questionnaire does not need any modification and is then considered final. The web address of the online survey questionnaire has been posted in the university's web-based learning environment (WBLE) in the form of a hyperlink. All the targeted respondents who are already the subscribers of the WBLE can access to the online survey questionnaire by clicking that hyperlink. A total of twelve statements about CSE and a question on gender are included in the survey questionnaire. The Likert scale $(1=$ strongly disagree, $2=$ disagree, $3=$ neither agree nor disagree, $4=$ agree, $5=$ strongly agree) is applied to each of the statements. Thus, the potential respondents will need to indicate their levels of agreement or disagreement with the statements about CSE. All questions require only an answer for each question. The respondents should answer all questions. One of the researchers has briefed the respondents about the questionnaire survey before they started to respond.

The questionnaire survey is conducted in the 2nd week of March 2015. A gentle reminder is sent out after a week since the data collection process started. All the 212 survey questionnaires, as the other 7 respondents who took part in the pilot study are excluded from the full-fledged survey, are collected in 10 days time. All the respondents have responded to the survey questionnaire and that all the questions have been answered. The response rate is $100 \%$. The 212 (males $=107$; females $=105$ ) fully completed survey questionnaires collected are analysed statistically. In defining the levels of awareness explicitly, four levels of awareness according to the calculated mean for each statement, specifically, $(1-2=$ slightly aware, $2.01-3=$ somewhat aware, $3.01-4=$ moderately aware, and $4.01-5=$ extremely aware) are derived. In addition, it is also very interesting to find out if there is a difference in terms of the levels of awareness on CSE between the male and female respondents. Thus, the null hypothesis: there is no difference in terms of the levels of awareness on CSE between the male and female respondents; and that the alternative hypothesis: there is a significant difference in terms of the levels of awareness on CSE between the male and female respondents are to be tested. 


\section{Results}

Table 1 shows the ranking of overall respondents' levels of awareness on CSE of HRCP in Malaysia. Frame (columns, upper floors) is ranked 1st with a mean of 3.93. Finishes (wall, ceiling and floor) are ranked 2nd with a mean of 3.59. External doors are ranked 3rd with a mean of 3.49. Envelope (external walls and windows) is ranked 4th with a mean of 3.42. Services are ranked 5th with a mean of 3.35. Internal subdivision (internal walls, screens and doors) is ranked 6th with a mean of 3.31. Preliminaries are ranked 7th with a mean of 3.21. Fittings are ranked 8th with a mean of 3.11. Stairs are ranked 9th with a mean of 2.98. Roof is ranked 10th with a mean of 2.77. External works are ranked 11th with a mean of 2.61. And lastly, substructure is ranked 12th with a mean of 2.13. Table 2 indicates the respondents' levels of awareness on CSE of HRCP in Malaysia based on gender. Apart from the differences in the ranking of the statements, both the male and female respondents perceived that frame (columns, upper floors) is the most significant building element affecting the HRCP cost in Malaysia, and they thought that roof, external works, and substructure are building elements that are of cost significance in the HRCP in Malaysia. Table 3 shows the results of the Mann-Whitney U test comparing the male and female respondents' levels of awareness on CSE of HRCP in Malaysia. For each of the 10 out of the total of 12 statements, namely, S02 to S04 and S06 to S12, the probability value (p) is not less than or equal to 0.05 , so the result is not significant. For each of the remaining 2 out of the total of 12 statements, namely, S01 and S05, the p-value is less than 0.05 , so the result is significant. This means that, generally; there is no statistically significant difference in the levels of awareness on CSE between the male and female respondents. Thus, the null hypothesis is accepted at a $95 \%$ confidence level and that the alternative hypothesis is rejected ( $\mathrm{p}$-value $>0.05$ ).

Table 1. Ranking of overall respondents' levels of awareness on CSE of HRCP in Malaysia.

\begin{tabular}{|l|c|c|c|}
\hline \multicolumn{1}{|c|}{ Statement } & Mean & $\begin{array}{c}\text { Standard } \\
\text { Deviation }\end{array}$ & Rank \\
\hline S02 - Frame (Columns, Upper Floors) is a cost significant element. & 3.93 & 0.818 & 1 \\
\hline $\begin{array}{l}\text { S08 - Finishes (Wall, Ceiling and Floor) are a cost significant } \\
\text { element. }\end{array}$ & 3.59 & 0.952 & 2 \\
\hline S06 - External Doors are NOT a cost significant element. & 3.49 & 0.990 & 3 \\
\hline $\begin{array}{l}\text { S04 - Envelope (External Walls and Windows) is a cost significant } \\
\text { element. }\end{array}$ & 3.42 & 0.983 & 4 \\
\hline S10 - Services are a cost significant element. & 3.35 & 0.984 & 5 \\
\hline $\begin{array}{l}\text { S07 - Internal Subdivision (Internal Walls, Screens and Doors) is a } \\
\text { cost significant element. }\end{array}$ & 3.31 & 0.953 & 6 \\
\hline S12 - Preliminaries are a cost significant element. & 3.21 & 1.041 & 7 \\
\hline S09 - Fittings are a cost significant element. & 3.11 & 1.033 & 8 \\
\hline S03 - Stairs are NOT a cost significant element. & 2.98 & 0.976 & 9 \\
\hline S05 - Roof is NOT a cost significant element. & 2.77 & 1.000 & 10 \\
\hline S11 - External Works are NOT a cost significant element. & 2.61 & 1.013 & 11 \\
\hline S01 - Substructure is NOT a cost significant element. & 2.13 & 0.866 & 12 \\
\hline
\end{tabular}

\section{Discussion}

The results reveal that both the male and female students have the same levels of awareness on CSE of HRCP in Malaysia. It therefore proves that gender is not a barrier in understanding the knowledge of construction particularly about CSE in this context. It also shows that the female students can also master the knowledge about construction as good as their male counterparts in an area which is male dominant from project conception to project completion. Based on this evidence, it has been expected that both the male and female students can equally provide advices on matters related to CSE. 
Table 2. Respondents' levels of awareness on CSE of HRCP in Malaysia based on gender.

\begin{tabular}{|c|c|c|c|c|c|c|}
\hline \multirow{3}{*}{ Statement } & \multicolumn{6}{|c|}{ Gender } \\
\hline & \multicolumn{2}{|r|}{ Male } & \multicolumn{2}{|r|}{ Female } & \multicolumn{2}{|r|}{ Total } \\
\hline & Mean & Standard Deviation & Mean & Standard Deviation & Mean & Standard Deviation \\
\hline S01 & 2.26 & 0.904 & 2.00 & 0.809 & 2.13 & 0.866 \\
\hline S02 & 3.92 & 0.859 & 3.95 & 0.777 & 3.93 & 0.818 \\
\hline S03 & 3.04 & 0.980 & 2.91 & 0.972 & 2.98 & 0.976 \\
\hline S04 & 3.37 & 0.957 & 3.48 & 1.010 & 3.42 & 0.983 \\
\hline S05 & 2.93 & 1.016 & 2.62 & 0.965 & 2.77 & 1.000 \\
\hline S06 & 3.60 & 0.999 & 3.37 & 0.973 & 3.49 & 0.990 \\
\hline S07 & 3.25 & 0.982 & 3.37 & 0.923 & 3.31 & 0.953 \\
\hline S08 & 3.55 & 0.954 & 3.63 & 0.953 & 3.59 & 0.952 \\
\hline S09 & 3.00 & 1.037 & 3.23 & 1.021 & 3.11 & 1.033 \\
\hline S10 & 3.41 & 1.027 & 3.30 & 0.940 & 3.35 & 0.984 \\
\hline S11 & 2.64 & 1.039 & 2.57 & 0.989 & 2.61 & 1.013 \\
\hline S12 & 3.19 & 1.100 & 3.23 & 0.983 & 3.21 & 1.041 \\
\hline
\end{tabular}

Table 3: Results of the Mann-Whitney U test comparing the male and female respondents' levels of awareness on CSE of HRCP in Malaysia

\begin{tabular}{ccccc}
\hline Statement & Mann-Whitney U & Wilcoxon W & $\mathbf{Z}$ & Asymptotic Significance (2-tailed) \\
\hline S01 & 4718.500 & 10283.500 & -2.219 & $0.026^{*}$ \\
S02 & 5589.500 & 11367.500 & -0.072 & 0.943 \\
S03 & 5123.500 & 10688.500 & -1.157 & 0.247 \\
S04 & 5137.500 & 10915.500 & -1.155 & 0.248 \\
S05 & 4626.000 & 10191.000 & -2.353 & $0.019 *$ \\
S06 & 4883.000 & 10448.000 & -1.728 & 0.084 \\
S07 & 5166.000 & 10944.000 & -1.073 & 0.283 \\
S08 & 5306.500 & 11084.500 & -0.766 & 0.444 \\
S09 & 4887.500 & 10665.500 & -1.710 & 0.087 \\
S10 & 5284.000 & 10849.000 & -0.792 & 0.428 \\
S11 & 5353.500 & 10918.500 & -0.634 & 0.526 \\
S12 & 5521.500 & 11299.500 & -0.224 & 0.823 \\
\hline
\end{tabular}

a. Grouping Variable: Gender

* Significant as p-value $<0.05$

On the one hand, the students are moderately aware that frame (columns, upper floors) is of cost significance. This may be because they understand that the frame is the building element that forms the building's skeleton [5] and it is usually made of reinforced concrete that is expensive. However, based on these very obvious reasons, it was expected that the students would be able to confidently tell or be extremely aware that the frame is indeed a cost significant element. This result signifies that there are some students who are still not very sure about it and therefore will affect their capabilities to advise others regarding the CSE of a project.

Finishes (wall, ceiling and floor) are another building element that has been perceived to be of cost significance. This could be because condominiums are luxurious residential units that will have large quantities of higher quality of internal finishes such as odourless paints for the wall finishes, plastered ceilings for the ceiling finishes, and homogeneous tiles for the floor finishes. The effects of the uses of different finishes on construction costs which have been stressed in the subjects like construction technologies are accounted for the students' understanding on this matter. Similarly, however, it was 
expected that they would be extremely aware that the finishes are in fact of cost significance. This result also shows that some students might not understand it as well as others. Nonetheless, the ability of the students in ranking the finishes as the next most important cost significant element after the frame worth complimenting as this is probably the case from what the researchers observed.

On the other hand, external doors are a building element that is not of cost significance seeing that they are usually less expensive than other building elements such as the frame and the finishes and are only in small quantities. Again, the students are only moderately aware of it. Indeed, this is the only non cost significant element which they are able to recognise. While recognising the CSE of HRCP is important, recognising those that are not of cost significance is equally important. So, when teaching the students, emphasis must be put in explaining the reasons why some building elements are CSE and the reasons why others are not. The students seem to be lack of confidence in this matter.

This scenario is evident as the students could not demonstrate that the building elements of stairs, roof, external works, and substructure are in fact not CSE for the HRCP. On top of that, the absence of statements about CSE that they are extremely aware of is worrying. This implies that the students are not performing well in this particular area. The overall mean for all the 12 statements on CSE is equal to 3.16, indicating that in general the students are merely moderately aware of the CSE of HRCP. This further reveals that their knowledge on CSE is rather weak and therefore improvements are necessary in order to enable them to be able to advise the project team members particularly the client or the developer professionally as early as during the internship when they are in their senior years of study or as soon as completing their study from the university.

While the learning outcomes related to the CSE are not provided explicitly in the syllabuses of the subjects of construction technologies, construction measurements and estimating, and construction economics, the student after studying these subjects should already gain some theoretical knowledge on CSE for a given project. This may be a new challenge for educators to instill relevant knowledge to their students but the desired result is achievable. Hence, it is recommended that the contents of CSE should be emphasised more in the relevant subjects and that their learning outcomes are to be written out clearly in the syllabuses. The students' improvements in this particular area will no doubt increase the competitiveness and add value to the profession. Besides that, workshops, seminars, and talks on CSE can also be organised for the sake of the students in the effort to increase the levels of awareness on CSE among the QS undergraduates.

\section{References}

[1] P.S.H. Poh and R.M.W. Horner, Cost-significant modelling - its potential for use in south-east Asia, Engineering, Construction and Architectural Management, 2(2), 121-139, (1995).

[2] E. Tas and H. Yaman, A building cost estimation model based on cost significant work packages, Engineering, Construction and Architectural Management, 12(3), 251-263, (2005).

[3] D. Cartlidge, Estimator's Pocket Book, Routledge, New York, (2013).

[4] J. Smith and D. Jaggar, Building Cost Planning for the Design Team, Butterworth-Heinemann, Burlington, (2007).

[5] M. Mehta, W. Scarborough and D. Armpriest, Building construction: Principles, Materials, and Systems, Pearson Education, New Jersey, (2003). 